\title{
Causes of cetacean stranding and death on the Catalonian coast (western Mediterranean Sea), 2012-2019
}

\author{
María Cuvertoret-Sanz ${ }^{1,2}$, Carlos López-Figueroa ${ }^{1,3}$, Alicia O'Byrne ${ }^{4}$, \\ Albert Canturri1 ${ }^{1,2}$, Bernat Martí-Garcia ${ }^{1,2}$, Ester Pintado ${ }^{1,2}$, Lola Pérez ${ }^{4}$, \\ Llilianne Ganges ${ }^{3}$, Alex Cobos $^{4}$, María Lourdes Abarca ${ }^{15}$, Juan Antonio Raga ${ }^{6}$, \\ Marie-Françoise Van Bressem ${ }^{7}$, Mariano Domingo ${ }^{1,2,3, *}$
}

\author{
${ }^{1}$ Departament de Sanitat i Anatomia Animals, Universitat Autònoma de Barcelona, 08193 Bellaterra, Spain \\ ${ }^{2}$ Servei de Diagnòstic de Patologia Veterinària, Universitat Autònoma de Barcelona, 08193 Bellaterra, Spain \\ ${ }^{3}$ IRTA, Centre de Recerca en Sanitat Animal, Campus de la Universitat Autònoma de Barcelona, 08193 Bellaterra, Spain \\ ${ }^{4}$ Facultat de Veterinària de Barcelona, Universitat Autònoma de Barcelona, 08193 Bellaterra, Spain \\ ${ }^{5}$ Veterinary Mycology Group, Facultat de Veterinària, Universitat Autònoma de Barcelona, 08193 Bellaterra, Spain \\ ${ }^{6}$ Marine Zoology Unit, Cavanilles Institute of Biodiversity and Evolutionary Biology, Science Park, University of Valencia, \\ PO Box 22085, 46071 Valencia, Spain \\ ${ }^{7}$ Cetacean Conservation Medicine Group, Peruvian Centre for Cetacean Research, Museo de Delfines, Lima 20, Peru
}

\begin{abstract}
The causes of cetacean stranding and death along the Catalan coast between 2012 and 2019 were systematically investigated. Necropsies and detailed pathological investigations were performed on 89 well-preserved stranded cetaceans, including 72 striped dolphins Stenella coeruleoalba, 9 Risso's dolphins Grampus griseus, 5 bottlenose dolphins Tursiops truncatus, 1 common dolphin Delphinus delphis, 1 Cuvier's beaked whale Ziphius cavirostris and 1 fin whale Balaenoptera physalus. The cause of death was determined for $89.9 \%$ of the stranded cetaceans. Fisheries interaction was the most frequent cause of death in striped dolphins (27.8\%) and bottlenose dolphins $(60 \%)$. Cetacean morbillivirus (CeMV) was detected on the Catalan coast from 2016 to 2017, causing systemic disease and death in 8 of the $72(11.1 \%)$ striped dolphins. Chronic CeMV infection of the central nervous system was observed from 2018-2019 in a further 5 striped dolphins. Thus, acute and chronic CeMV disease caused mortality in $18 \%$ of striped dolphins and $14.6 \%$ of all 89 cetaceans. Brucella ceti was isolated in 6 striped dolphins and 1 bottlenose dolphin with typical brucellosis lesions and in 1 striped dolphin with systemic CeMV. Sinusitis due to severe infestation by the nematode parasite Crassicauda grampicola caused the death of 4 out of 6 adult Risso's dolphins. Maternal separation, in some cases complicated with septicemia, was a frequent cause of death in 13 of 14 calves. Other less common causes of death were encephalomalacia of unknown origin, septicemia, peritonitis due to gastric perforation by parasites and hepatitis caused by Sarcocystis spp.
\end{abstract}

KEY WORDS: Causes of death - Mediterranean Sea - Cetaceans - Morbillivirus - CeMV · Brucella ceti $\cdot$ Brucellosis $\cdot$ Necropsy $\cdot$ Strandings $\cdot$ Fisheries

\section{INTRODUCTION}

Awareness of the impact of human activities and natural disease on odontocetes and mysticetes is in-

*Corresponding author: mariano.domingo@uab.cat creasing in the Mediterranean Sea (Bearzi 2002, Van Bressem et al. 2009, Di Guardo et al. 2011, Avila et al. 2018). Fisheries have caused the death of thousands of dolphins (mostly common dolphins Delphinus del- 
phis, common bottlenose dolphins Tursiops truncatus and striped dolphins Stenella coeruleoalba) and have severely reduced populations of these species (Silvani et al. 1999, Tudela et al. 2005, Hammond et al. 2008, Bearzi et al. 2012). Collision with vessels is another important cause of mortality, especially in large cetaceans such as fin whales Balaenoptera physalus and sperm whales Physeter macrocephalus (Panigada et al. 2006, Notarbartolo-Di-Sciara 2014). In addition, high loads of chemical pollutants detected in the tissues of several species may reduce their immune response and impair reproduction (Aguilar \& Borrell 1994, Storelli et al. 2007, Law 2014, Pinzone et al. 2015, Schoeman et al. 2020). As a consequence, several species are considered vulnerable or severely endangered by the International Union for Conservation of Nature (IUCN) (Aguilar \& Gaspari 2012, Bearzi et al. 2012, Panigada \& Notarbartolo-di-Sciara 2012).

Several infectious and parasitic diseases have been described in cetaceans in the western Mediterranean Sea, including cetacean morbillivirus (CeMV), brucellosis, mycoses such as aspergillosis and mucormycois, toxoplasmosis and crassicaudiasis (Raga et al. 1982, Domingo et al. 1990, 1992, Alba et al. 2013). However, global results of monitoring have not been published to date, and the relative impact of anthropogenic factors and natural diseases on cetaceans in this area is unknown.

CeMV has caused 2 major outbreaks of mortality in the western Mediterranean; in 1990-1992 and 20062007 (Domingo et al. 1990, Van Bressem et al. 1991, Raga et al. 2008). Although the striped dolphin was the species most affected by both outbreaks, common dolphins, common bottlenose dolphins, pilot whales, minke whales and fin whales also suffered mortality (Van Bressem et al. 2014). Cases of encephalitis associated with CeMV were regularly detected in the 2-3 years following the outbreaks (Domingo et al. 1995, Soto et al. 2011a). Though the virus does not seem to be endemic in Mediterranean cetaceans, it may be periodically introduced into this area by Atlantic cetaceans crossing the Gibraltar Strait (Van Bressem et al. 2014).

Early studies in the Mediterranean Sea reported serological evidence of Brucella spp. infection as early as 1997-1999 in striped dolphins from the Valencian coast (Van Bressem et al. 2001). The disease was subsequently detected in cetaceans stranded along the coasts of Italy, Spain and Croatia (Alba et al. 2013, Garofolo et al. 2014, Isidoro-Ayza et al. 2014, Cvetnić et al. 2016), suggesting that brucellosis is probably endemic in cetaceans from the Mediterranean Sea (Pintore et al. 2018).
To better understand the causes of cetacean mortality in the western Mediterranean Sea, our group has routinely examined all necropsied cetaceans for CeMV and Brucella spp. infection, as well as for parasitic infestation and the presence of anthropogenic injuries since 1990. Here we report on the results of necropsy, histopathology and laboratory investigations performed on 89 cetaceans stranded along the Catalonian coast (western Mediterranean) between 2012 and 2019.

\section{MATERIALS AND METHODS}

\subsection{Cetaceans and necropsy procedure}

Between 2012 and 2019, a total of 89 cetaceans stranded along the Catalonian coast were necropsied at the Veterinary School of the Universitat Autònoma de Barcelona (UAB) by ECVP-certified pathologists, according to established procedures (Kuiken 1991). Specimen condition ranged from 1 (recently dead) to 3 (moderately decomposed) (Kuiken 1991). Age class (calf, juvenile, adult) was estimated using body length, colour and presence of fetal folds for very young calves, according to previous works (Bearzi et al. 1997, 2011, Calzada et al. 1997). Cardiac blood was collected immediately upon reception of the cadaver through a cardiac puncture at the central point of a coronal line from sternum to axillar fold, using a $20 \mathrm{ml}$ syringe and a $16 \mathrm{G}, 1.7 \times 133 \mathrm{~mm}$ catheter needle (AngiocathTM). Blood samples were portioned in vacutainer plain tubes. Blood was centrifuged at $2500 \times g$ and serum samples were aliquoted in $1 \mathrm{ml}$ cryotubes and frozen at $-80^{\circ} \mathrm{C}$ until use. Computed tomography (CT) scans were performed on 6 freshly dead striped dolphins at the UAB Veterinary Teaching Hospital to obtain information on image diagnosis and as an aid to diagnose peracute underwater entrapment (PUE). Cerebrospinal fluid (CSF) was collected via a dorsal puncture of the atlanto-occipital joint after the removal of the dorsal muscular planes, or, if present, directly from the lateral ventricle after brain extraction. A complete set of tissue samples was collected for histopathology, fixed in $10 \%$ neutral buffered formalin and processed using standard procedures. Diagnosis of fisheries interactions and anthropogenic injuries followed established criteria (Van Waerebeek et al. 2007, Moore et al. 2013, Bernaldo de Quirós et al. 2018). Maternal separation was diagnosed in neonates and calves following the exclusion of any other disease. Parasites were identified morphologically to 
the family or genus level or ascribed to a defined species if the morphology and location were highly specific.

\subsection{Bacteriological investigation}

Samples and swabs from different organs (lung, liver, spleen, kidney, brain, intestine) were collected for bacteriological investigation. Homogenates of tissue samples were inoculated onto Columbia agar with $5 \%$ sheep blood (Difco) and MacConkey agar (Oxoid) and incubated overnight at $37^{\circ} \mathrm{C}$ in $5 \%$ $\mathrm{CO}_{2}$. When mycological infection was suspected, samples were also cultured in Sabouraud dextrose agar (Oxoid) with chloramphenicol and incubated at $25^{\circ} \mathrm{C}$ for $7 \mathrm{~d}$. Gram-negative bacteria were phenotypically identified using the API20E and API20NE identification system (bioMérieux). Fungal identification was achieved through macroscopic and microscopic studies in accordance with the codes published for each genus.

\subsection{CeMV detection}

Immunohistochemistry (IHC) to detect CeMV was performed on samples of lung, diaphragmatic lymph node and brain following Soto et al. (2011b). Procedures were adapted to the platform Dako Autostainer Plus using buffers and reagents provided by the manufacturer. Briefly, slides were transferred to a PT-Link Automatic System (Dako) for deparaffinization, rehydration and epitope retrieval (acid buffer at $\mathrm{pH} 6$ for $20 \mathrm{~min}$ at $98^{\circ} \mathrm{C}$ ). A MoAb against the nucleoprotein of canine distemper virus (CDV), known to cross-react with CeMV (VMRD, $1 \mathrm{mg} \mathrm{ml}^{-1}$, IgG2b, kappa light chain), was incubated for $40 \mathrm{~min}$ at room temperature, diluted 1:5000 in EnVision ${ }^{\mathrm{TM}}$ FLEX buffer. After washing, the rabbit/mouse EnVision Detection System (Dako) was incubated at room temperature for $40 \mathrm{~min}$ at the dilution recommended by the manufacturer. Slides were then washed and incubated for $5 \mathrm{~min}$ in 3, 3'-diaminobenzidine (DAB) chromogen-hydrogen peroxide (Dako) to reveal binding, counterstained in Mayer's haematoxylin, and then automatically dehydrated, cleared and mounted. A slide of a known CeMV-positive cetacean was used as a positive control. As a negative control the same tissue was used, but the first antibody was omitted.

Conventional RT-PCR for detection of CeMV was performed on samples of lung, diaphragmatic lymph node, spleen and brain tissue following established protocols of 1-step RT-PCR for a $78 \mathrm{bp}$ fragment of the phosphoprotein (P) gene (Krafft et al. 1995).

\subsection{Detection of Brucella infection}

Undiluted cetacean serum samples were investigated using the Bengal Rose test (BRT) following OIE-established (OIE 2019) immediately after collection of the sample from living stranded cetaceans, or before necropsy on the sera obtained from cardiac blood. Aliquots of the sera were also retested by the Laboratorio de Brucellosis del CITA de Aragón to confirm results. Brucella isolation, considered the gold standard for brucellosis diagnosis, was attempted in 21 cases selected according to the following criteria: (1) positivity in the BRT or Brucella-C-ELISA (data not shown), (2) presence of lesions compatible with $B$. ceti infection or (3) systemic CeMV infection detected by RT-PCR or IHC. The set of samples and tissues for Brucella culture included frozen swabs from a lateral cerebral ventricle, cerebral tissue around the lateral ventricle, spleen, mesenteric lymph node, swabs from spondylitis lesions and cerebrospinal fluid (CSF). Bacterial isolation was performed as described in previous studies (IsidoroAyza et al. 2014).

\section{RESULTS}

Between January 2012 and December 2019, a total of 289 cetaceans from 7 species stranded along the coast of Catalonia. Thirty-three individuals (11\%) could not be identified to species level due to the poor condition of the cadaver. Necropsies and detailed pathological investigations were performed on 89 (31\%) cetaceans, including 42 females and 47 males, belonging to 6 species: Stenella coeruleoalba $(\mathrm{n}=72)$, Grampus griseus $(\mathrm{n}=9)$, Tursiops truncatus $(\mathrm{n}=5)$, Delphinus delphis $(\mathrm{n}=1)$, Ziphius cavirostris $(\mathrm{n}=1)$ and Balaenoptera physalus $(\mathrm{n}=1)$. The number of stranded and necropsied cetaceans by year and species is shown in Table 1. Of these 89 individuals, 23 $(25.8 \%)$ were found alive and died shortly after stranding or were euthanised due to poor prognosis. The cause of stranding/death could not be determined in 9 cases $(10.1 \%$, 7 striped dolphins, 1 Risso's dolphin, and 1 common dolphin). Neoplastic lesions were not found in any of the necropsied cetaceans. A summary of causes of stranding/death for the 89 
Table 1. Cetaceans found stranded along the coast of Catalonia, Spain, and necropsied between 2012 and 2019

\begin{tabular}{|lccccccccccc}
\hline & 2012 & 2013 & 2014 & 2015 & 2016 & 2017 & 2018 & 2019 & Total \\
\hline Stranded & & & & & & & & & \\
Stenella coeruleoalba & 39 & 11 & 14 & 21 & 20 & 34 & 34 & 11 & 184 \\
Tursiops truncatus & 9 & 4 & 3 & 3 & 4 & 1 & 6 & 3 & 33 \\
Grampus griseus & 4 & 2 & 1 & 2 & 8 & & & 1 & 18 \\
Balaenoptera physalus & 1 & 1 & & 1 & 5 & 1 & 2 & 1 & 12 \\
$\begin{array}{l}\text { Physeter macrocephalus } \\
\text { Ziphius cavirostris }\end{array}$ & 1 & 1 & 1 & & & & 1 & 4 \\
Delphinus delphis & 1 & & & 2 & & & & 1 & 3 \\
Unidentified species & 9 & 5 & 2 & 7 & 1 & 1 & 6 & 2 & 33 \\
Total & $\mathbf{6 3}$ & $\mathbf{2 4}$ & $\mathbf{2 1}$ & $\mathbf{3 7}$ & $\mathbf{3 8}$ & $\mathbf{3 8}$ & $\mathbf{4 8}$ & $\mathbf{2 0}$ & $\mathbf{2 8 9}$ \\
Necropsied & & & & & & & & & \\
Stenella coeruleoalba & 15 & 1 & 6 & 6 & 5 & 16 & 18 & 5 & 72 \\
Tursiops truncatus & 3 & & & & 1 & & 1 & & 5 \\
Grampus griseus & 1 & 2 & & & 5 & & & 1 & 9 \\
Balaenoptera physalus & & & & 1 & & & & & 1 \\
Physeter macrocephalus & & & & & & & & 1 & 1 \\
$\begin{array}{l}\text { Ziphius cavirostris } \\
\text { Delphinus delphis }\end{array}$ & & & & & & & & 1 & & 1 \\
Total & $\mathbf{1 9}$ & $\mathbf{3}$ & $\mathbf{6}$ & $\mathbf{7}$ & $\mathbf{1 1}$ & $\mathbf{1 7}$ & $\mathbf{1 9}$ & $\mathbf{7}$ & $\mathbf{8 9}$ \\
\hline
\end{tabular}

Table 2. Cause of death or stranding for 89 cetaceans stranded between 2012 and 2019 on the Catalonian coast. Sc: Stenella coeruleoalba; Gg: Grampus griseus; Tt: Tursiops truncatus; Dd: Delphinus delphis; Bp: Balaenoptera physalus; Zc: Ziphius cavirostris

\begin{tabular}{|c|c|c|c|c|c|c|c|}
\hline Cause of death/stranding & $\mathrm{Sc}$ & $\mathrm{Gg}$ & $\mathrm{Tt}$ & $\mathrm{Dd}$ & $\mathrm{Bp}$ & $\mathrm{Zc}_{\mathrm{c}}$ & Total \\
\hline Fisheries interaction & 20 & 1 & 3 & & & & 24 \\
\hline Maternal separation & 8 & 1 & & & 1 & & 10 \\
\hline Systemic CeMV disease & 7 & & & & & & 7 \\
\hline $\begin{array}{l}\text { Systemic CeMV disease + } \\
\text { brucellosis }\end{array}$ & 1 & & & & & & 1 \\
\hline CNS CeMV disease & 5 & & & & & & 5 \\
\hline Brucella meningitis & 6 & & & & & & 6 \\
\hline Septicaemia & 4 & 2 & & & & & 6 \\
\hline $\begin{array}{l}\text { Sinusitis by Crassicauda } \\
\text { grampicola }\end{array}$ & & 4 & & & & & 4 \\
\hline CNS Malacia & 3 & & & & & & 3 \\
\hline Protozoal dermatitis & 2 & & 1 & & & & 3 \\
\hline $\begin{array}{l}\text { Trauma (intra- or } \\
\text { interspecific interaction) }\end{array}$ & 1 & & & & & 1 & 2 \\
\hline Bacterial meningitis & 1 & & & & & & 1 \\
\hline Pneumothorax & 1 & & & & & & 1 \\
\hline Hepatic sarcocystosis & 1 & & & & & & 1 \\
\hline Spondylosis & 1 & & & & & & 1 \\
\hline $\begin{array}{l}\text { Spondylosis by Brucella }+ \\
\text { CNS mucormycosis }\end{array}$ & & & 1 & & & & 1 \\
\hline Peritonitis & 1 & & & & & & 1 \\
\hline $\begin{array}{l}\text { Meningoencephalitis of } \\
\text { unknown cause }\end{array}$ & 3 & & & & & & 3 \\
\hline Unknown & 7 & 1 & & 1 & & & 9 \\
\hline Total & 72 & 9 & 5 & 1 & 1 & 1 & 89 \\
\hline
\end{tabular}

necropsied cetaceans is shown in Table 2. Individual data, including biometrics and results of pathological investigations, for the necropsied cetaceans are shown in the Supplement at www.int-res.com/articles/suppl/d142 p239_supp.xlsx.

\subsection{Anthropogenic mortality}

Evidence of fisheries interaction as the cause of death was found in 24 of $89(27 \%)$ individuals, including 20 striped dolphins $(27.8 \%, \mathrm{n}=72), 3$ bottlenose dolphins $(60 \%, \mathrm{n}=5)$ and 1 Risso's dolphin (11.1\%, $\mathrm{n}=9$ ). These individuals were either reported as bycatch by fishermen or had abundant undigested prey in the forestomach, together with mutilations, sharp cuts or net marks. Gas bubble formation, a consequence of PUE (Bernaldo de Quirós et al. 2018), was observed in a CT scan of a freshly dead striped dolphin. Widespread gas bubble formation was found in many organs and tissues in comparison with the CT scan of another striped dolphin that had died of another cause (Fig. 1). Gas bubbles were also macroscopically detected in the mesenteric veins or subcutaneous tissue of a few animals (Fig. 2A). Histologically, gas bubbles were observed in 10 of the 24 dolphins that had died as a result of fisheries interactions, especially in the subcapsular sinus of the diaphragmatic and mesenteric lymph nodes and in brain tissue and vessels (Fig. 2B,C). Based on these findings, the cause of mortality in individuals with gas bubbles in tissues was classified as human interaction with associated PUE (Moore et al. 2013, De Quirós et al. 2018).

\subsection{CeMV infection}

Eight cases of systemic CeMV infection were observed in striped dolphins between September 2016 and September 2017. During the following years, 5 additional striped dolphins died of chronic central nervous system (CNS)-localized CeMV disease. In these 5 cases, the brain was positive for CeMV using RT-PCR and IHC, but the other tissues (lungs, lymph nodes and spleen) were negative (Fig. 3A,B). Thus, CeMV accounted for the 

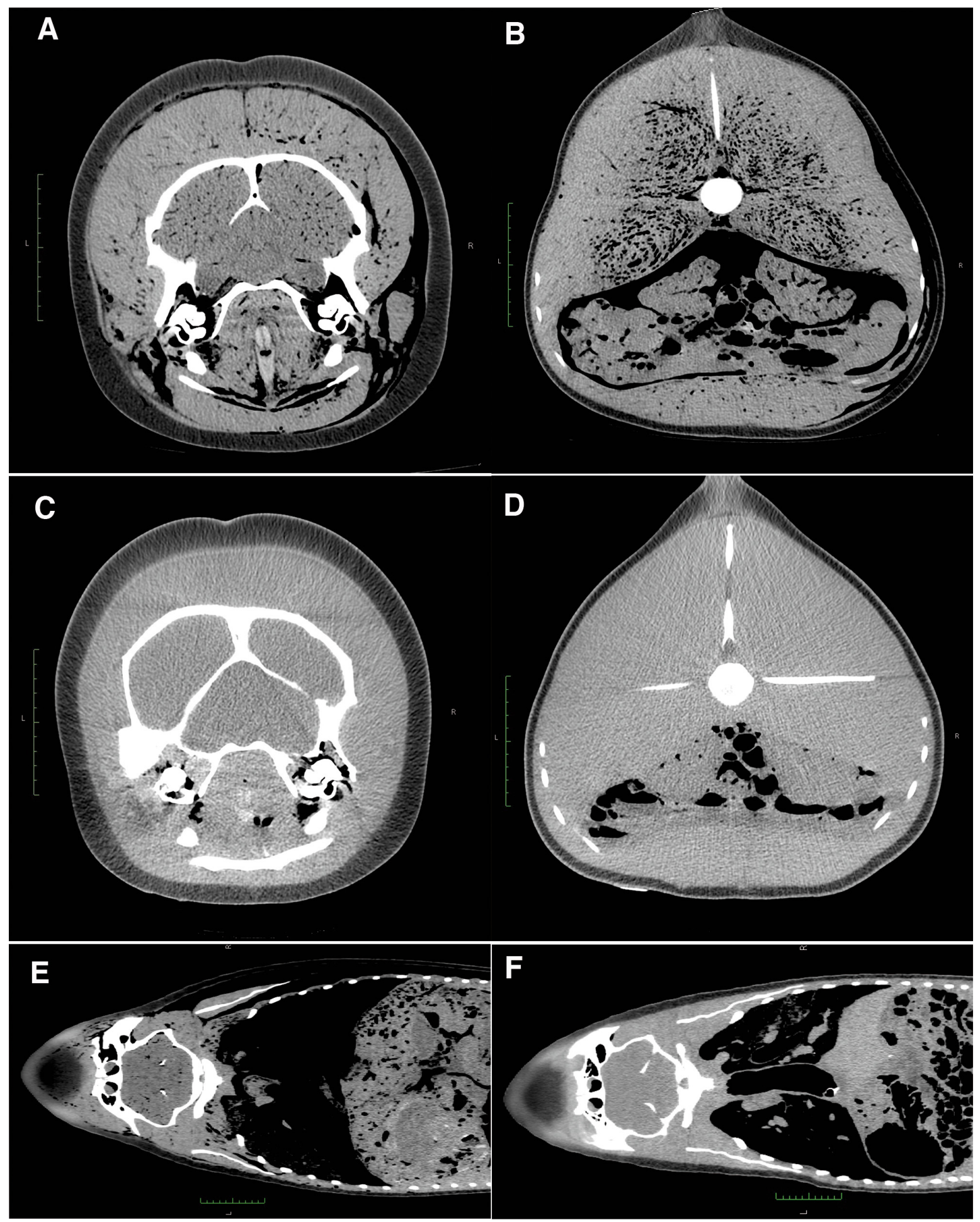

Fig. 1. Computed tomography (CT) scan of a striped dolphin that died through peracute underwater entrapment (PUE) (N-375/18) compared with an individual that died of septicemia (N-407/15). (A) Transverse plane of the head of N-375/18 at the level of the tympanic bullae showing several small gas bubbles in the nervous tissue and meningeal spaces as well as in the muscular tissue of the head. (B) Transverse plane of N-375/18 at the level of the kidneys showing several gas bubbles in muscular and renal tissues and in the peritoneal space. (C) Transverse plane of the head of N-407/15 at the level of the tympanic bullae for comparison. (D) Transverse plane of N-407/15 at the level of the kidneys for comparison. (E) Coronal plane of the anterior part of N-375/18 showing subcutaneous emphysema and large gas bubbles in hepatic tissue (vessels). (F) Coronal plane of the anterior part of $\mathrm{N}-407 / 15$ for comparison 

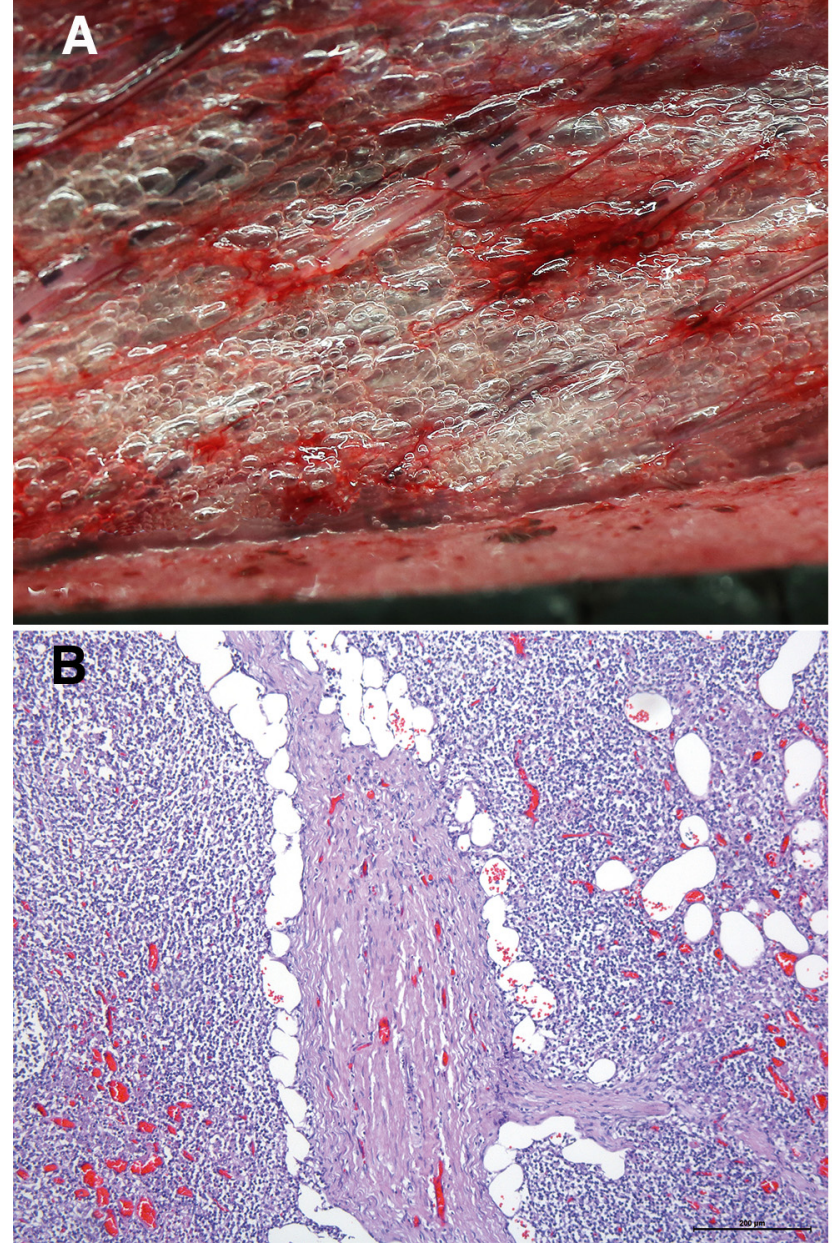

death of $14.6 \%$ of all necropsied cetaceans, and $18 \%$ of the 72 striped dolphins. Three of the 8 systemic cases presented characteristic interstitial pneumonia, lymphoid depletion and encephalitis, with strong IHC staining for CeMV, and tested positive for CeMV using RT-PCR in the target organs. In an additional 4 systemic CeMV cases, focal or multifocal granulomatous-necrotizing mycotic encephalitis was the main lesion (Fig. 3C). Aspergillus fumigatus was cultured and identified phenotypically in 3 of the 8 systemic-CeMV cases. Culture could not be attempted in the fourth case, because the lesion was discovered after fixation and slicing of the brain. These 4 dolphins did not show characteristic histological CeMV lesions (bronchointersticial pneumonia, lymphoid depletion, mononuclear encephalitis) and were negative for CeMV using IHC. CeMV infection could only be detected by RT-PCR in the lungs, diaphragmatic lymph nodes and CNS. CeMV infection was solely detected in striped dolphins, but only 1 specimen of

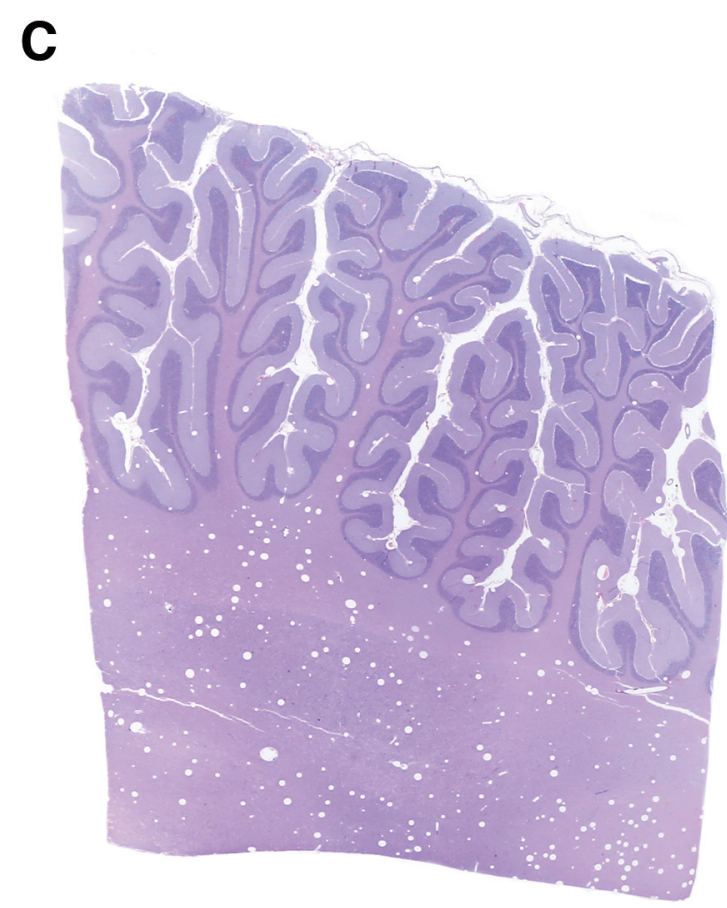

Fig. 2. Tissue samples of striped dolphins that died through peracute underwater entrapment (PUE). (A) subcutaneous tissue showing gas bubbles (dolphin N-375/18). (B) Diaphragmatic lymph node, histological section at low magnification showing subcapsular sinuses distended by gas bubbles (N-375/18). H\&E. (C) Submacroscopic image of a cerebellar section showing large vacuoles preferentially located in the white substance (N-556/12). H\&E

another species, a common dolphin, was necropsied during the period of CeMV circulation.

\subsection{Brucella ceti}

Lesions and disease attributable to $B$. ceti were detected in 6 striped dolphins and 1 bottlenose dolphin. All 6 striped dolphins had characteristic neurobrucellosis histologic lesions (diffuse severe lymphohistiocytic meningitis) and turbid CSF, indicative of high cellularity (Fig. 3D). In addition, B. ceti was cultured from the brain ventricular swabs of another striped dolphin (N-319/16) that had systemic CeMV disease, including lymphohistiocytic encephalitis associated with CeMV, but no meningitis. Some data from 2 of these cases (N-275/12 and N-301/12) were previously published (Isidoro-Ayza et al. 2014). In the 7 striped dolphins, $B$. ceti was isolated from brain samples, ventricular swabs or the CSF. The bottlenose dolphin (N275/12) had ankylosing spondylitis, together with 

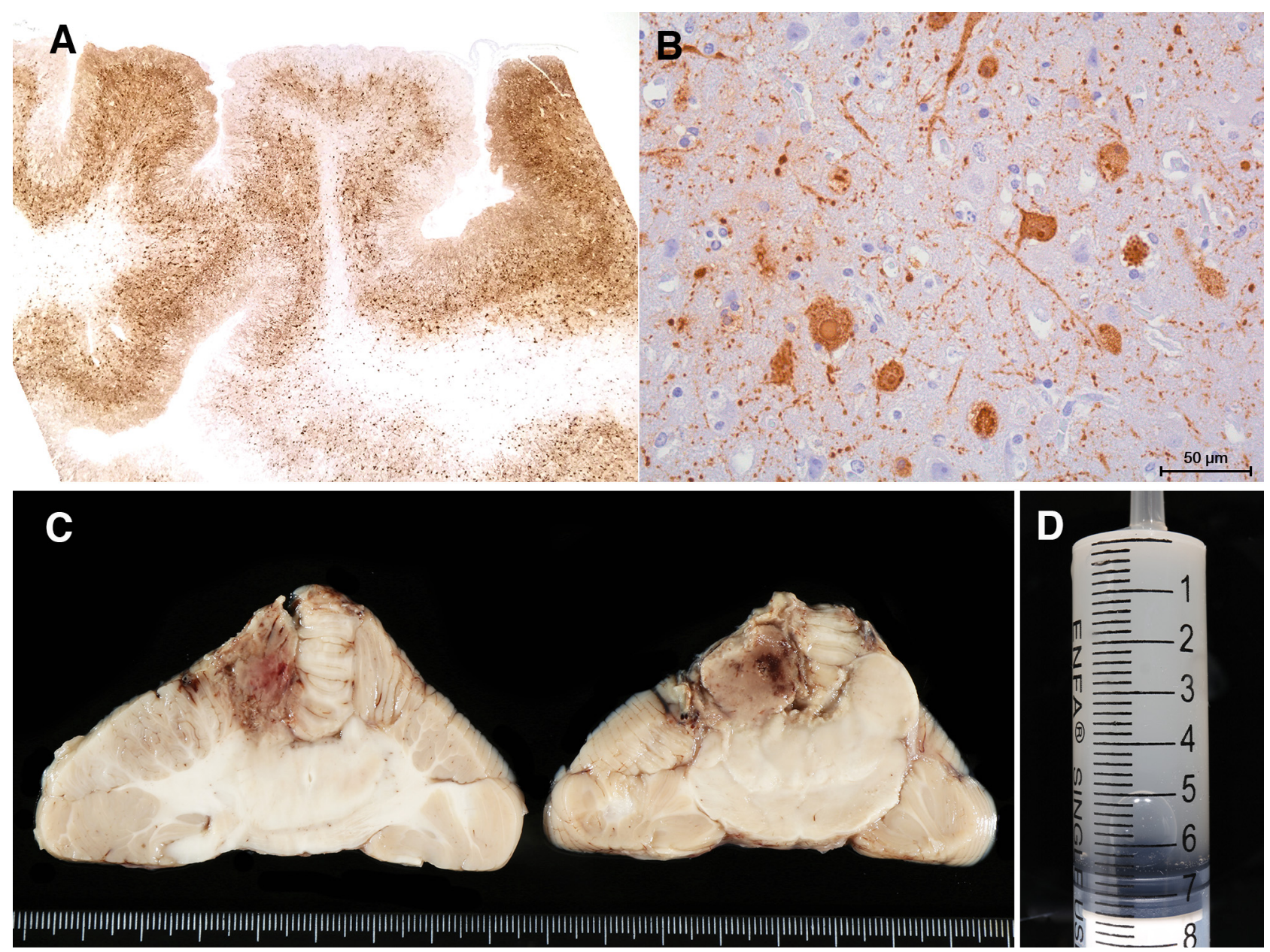

Fig. 3. (A) Striped dolphin with chronic CeMV of the CNS. IHC for CeMV, low magnification, showing preferent cortical distribution of immunostaining in a laminar pattern. (B) High magnification of (A) showing presence of CeMV antigen in neurons and cellular processes. DAB immunostaining, hematoxylin counterstained. (C)Striped dolphin cerebellum showing granulomatous-necrotizing encephalitis caused by fungal growth as a result of infection by CeMV. Fixed in formalin. (D) Striped dolphin Brucella ceti meningitis, cerebrospinal fluid (CSF) obtained by atlanto-occipital puncture. The CSF is turbid, indicating high cellularity (meningitis)

granulomatous encephalitis caused by a mucormycosis that was probably the cause of death. $B$. ceti was successfully isolated from a swab of the dyscospondylitic lesion. Biometric and pathological data for cetaceans with a positive Brucella culture are shown in Table 3. Brucella isolation was attempted retrospectively in frozen samples from 13 additional cases (see the criteria in section 2.4), but was negative in all cases. Hence, Brucella lesions and disease were found in 7 of 89 ( $7.8 \%)$ cetaceans, and Brucella isolation was successful only in 8 of 21 (38\%) cetaceans investigated by bacteriologic culture. The BRT was positive in all 8 cetaceans where $B$. ceti was successfully isolated but was also positive in 8 additional striped dolphins and 2 Risso's dolphins, all of them with a cause of death unrelated to B. ceti (see the Supplement).

\subsection{Calf mortality}

Maternal separation and bacterial sepsis were responsible for the stranding of 13 neonates and calves (9 striped dolphins, 3 Risso's dolphins, and 1 fin whale). These animals often had different degrees of hepatic lipidosis. Sepsis was diagnosed in 3 calves, based on the isolation of abundant bacterial colonies in several parenchymatous organs. In case N-298/16, a Risso's dolphin calf, bacterial aggregates were seen in many capillary vessels in the brain without associated lesions, and Photobacterium damselae and Vibrio parahaemolyticus were isolated from most of the organs tested. A striped dolphin calf (N-523/17) had bacteria in lung alveolar spaces, with an increased number of mononuclear cells in alveo- 
Table 3. Biometric and pathological characteristics of cetaceans from which Brucella ceti was isolated. The BRT was positive for all dolphins, and one dolphin also had CeMV systemic disease. Tt: Tursiops truncatus; Sc: Stenella coeruleoalba; D: dead; A: alive; M: males; F: female; P: positive; N: negative

\begin{tabular}{|c|c|c|c|c|c|c|}
\hline ID & Species & Stranded & Gender & Length & CeMV & Lesions \\
\hline N-275/12 & $\mathrm{Tt}$ & $\mathrm{D}$ & M & 300 & $\mathrm{~N}$ & $\begin{array}{l}\text { Spondylitis and } \\
\text { Mucormycosis in CNS }\end{array}$ \\
\hline N-301/12 & $\mathrm{Sc}$ & $\mathrm{A}$ & $\mathrm{F}$ & 184 & $\mathrm{~N}$ & Mononuclear meningitis \\
\hline N-260/16 & $\mathrm{Sc}$ & $\mathrm{D}$ & $\mathrm{F}$ & 170 & $\mathrm{~N}$ & $\begin{array}{l}\text { Mononuclear meningitis } \\
\text { serous atrophy of fat }\end{array}$ \\
\hline N-319/16 & $\mathrm{Sc}$ & A & $\mathrm{F}$ & 180 & $\mathrm{P}$ & CeMV encephalitis \\
\hline N-168/17 & $\mathrm{Sc}$ & $\mathrm{A}$ & M & 193 & $\mathrm{~N}$ & Mononuclear meningitis \\
\hline N-274-18 & $\mathrm{Sc}$ & A & M & 152 & $\mathrm{~N}$ & Mononuclear meningitis \\
\hline N-314-19 & $\mathrm{Sc}$ & $\mathrm{A}$ & $\mathrm{F}$ & 159 & $\mathrm{~N}$ & Mononuclear meningitis \\
\hline N-368-19 & $\mathrm{Sc}$ & A & M & 175 & $\mathrm{~N}$ & Mononuclear meningitis \\
\hline
\end{tabular}

hepatopancreatic ducts, Brachycladiidae, (Mateu et al. 2011, Fraija-Fernández et al. 2016) were also frequently found, causing nodular lesions in the secretory stomach chambers and inflammation in and around the hepatopancreatic ducts. In one pregnant striped dolphin (N-258/19), these parasitic lesions caused the perforation of the gastric wall, leading to peritonitis and death. Only one case of gastritis (forestomach) due to Anisakidae was observed in a striped dolphin (N68/15).

lar lumens and in the subcapsular sinuses of the diaphragmatic lymph node. Photobacterium damselae was isolated from most organs submitted. A Risso's dolphin calf $(\mathrm{N}-255 / 13)$ that stranded alive died $3 \mathrm{~d}$ later, after being moved to a rescue pool, due to pneumonia and sepsis caused by Aeromonas dhakensis (Pérez et al. 2015). Some calves had ingested foreign materials (e.g. sand or invertebrates), but these materials did not appear to cause lesions (Lacombe et al. 2020).

\subsection{Parasitic lesions}

External and internal (in dermis, respiratory and digestive systems and air sinuses, as well as subperitoneal) parasites were frequently encountered, but only some of them were associated with significant pathogenic effects. Crustacean epibionts (amphipods, copepods and cirripeds) were often found in small numbers on the skin and in natural body openings. High numbers of these epibionts were considered to be evidence of lowered host mobility and frequently were associated with the detection of chronic debilitating disease (Aznar et al. 1994, 2005). Larval forms of the cestodes Clistobothrium, delphini or grimaldii morphotypes (formerly Phyllobothrium delphini, in blubber, and Monorygma grimaldii, sub-peritoneal) (Klotz et al. 2018) were common in their customary locations in juvenile and adult delphinids, and considered apathogenic. Lung nematodes were also frequently detected in juvenile and adult individuals, but lesion severity was low, and they were considered of low pathogenicity. The trematodes of the secretory stomach, Pholeter gastrophilus, (Fraija-Fernández et al. 2017) and of the
The adult cestode Strobilocephalus triangularis infested the intestine of 4 striped dolphins (N-556/12, $\mathrm{N}-009 / 14, \mathrm{~N}-168 / 17$ and N-214/19) during the study period, and at least 2 more cases were recorded between 1995 and 2012. S. triangularis is easy to identify morphologically due to its large globous scolex, which it embeds in the intestinal mucosa (Mateu et al. 2014). Striking similarities were observed in all 4 cases of $S$. triangularis infestation. The parasites were located in a short fragment of intestine, about $15 \mathrm{~cm}$ in length and approximately 20$30 \mathrm{~cm}$ from the rectal tonsil. Externally, they were visualized as an ovoid regular enlargement of the intestine, without intestinal obstruction. When the intestine was opened, the globous scolexes protruded as $0.5-1 \mathrm{~cm}$ spherical masses in the intestinal mucosa, with the strobila in the intestinal lumen. At section, the scolexes were found beneath the intestinal mucosa, in the submucosa, limited by the muscular layers (Fig. 4A,B). The inflammatory response around the parasite was of low intensity, but some scolexes showed involution and were associated with a suppurative reaction.

Four adult Risso's dolphins (3 males and 1 female, between 290 and $316 \mathrm{~cm}$ length) likely stranded following bilateral paraotic sinusitis caused by severe Crassicauda grampicola infestation, identified by gross morphology and anatomical location. All dolphins stranded alive and died shortly after. The parasites infested the lumen of the pterygoid sinuses bilaterally (Fig. 4C) and perforated the mucosa, remaining coiled between the bony surface and the submucosa of the sinus. This caused severe inflammatory changes in the sinus mucosa and submucosa, as well as osteolysis. Mild C. grampicola infection was also found in 2 additional adult Risso's 

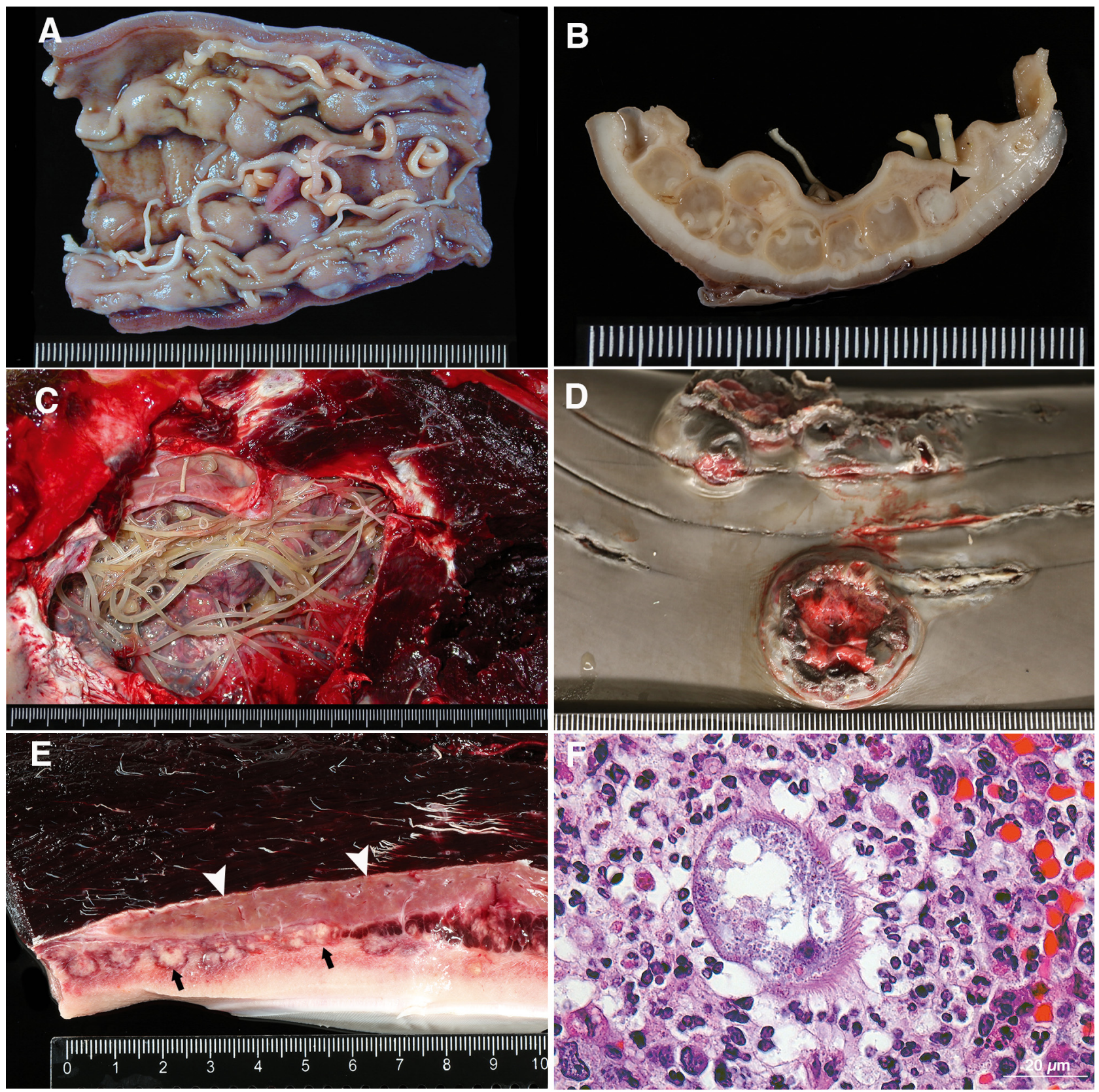

Fig. 4. Parasite lesions in cetaceans. (A) Striped dolphin intestine (colon-rectum) opened longitudinally, showing prominent nodular scolexes of Strobilocephalus triangularis. The strobila are visible, free in the intestinal lumen. Sample prefixed in formalin. (B) Transverse section of (A) showing spherical scolexes beneath the intestinal mucosa and over the muscular layers. One scolex is in involution due to the host inflammatory reaction (arrowhead). (C) A ventro-lateral view of an opened paraotic sinus from a Risso's dolphin, showing adult forms of Crassicauda grampicola. (D) Bottlenose dolphin skin showing ulcerative dermatitis associated with tooth rakes. (E) Sagittal plane through abdominal blubber, mammary gland (white arrowheads) and abdominal musculature of a striped dolphin, showing multinodular inflammatory lesions in the blubber and subcutaneous muscles (black arrows). (F) Pyogranulomatous inflammatory infiltrate with a protozoan parasite from a striped dolphin

dolphins, but it was not considered to be the cause of stranding. While one of them died following accidental capture, the cause of death of the other one was unknown.
An apicomplexan protozoon identified morphologically as Sarcocystis spp. caused fatal hepatitis in 1 adult striped dolphin (N-029/15), which also had a unilateral pneumothorax. Lesions as- 
sociated with ciliated protozoans were detected in 2 striped dolphins (N-68/15 and N-511/18) and 1 bottlenose dolphin (N-521/18). Cutaneous lesions, frequently ulcerated, were commonly found associated with tooth-rakes or with perforation by Pennella balaenoptera, a large copepod parasite (Fraija-Fernández et al. 2018) (Fig. 4D). Internal pyo-granulomatous inflammatory foci associated with $30 \times 40 \mu \mathrm{m}$ ciliated protozoans (probably Kyaroikeus spp. or Planilamina spp.) were also observed in blubber and striated muscle close to the initial skin lesions in these dolphins (Fig. 4E,F). The cause of death, in absence of other significant lesions or diseases, was tentatively ascribed to the protozoan.

\subsection{Other infectious causes of mortality}

Septicemia caused by $P$. damselae, Moraxella spp. and Vibrio alginolyticus was detected in 3 adult striped dolphins. A striped dolphin had a focal meningitis due to Actinobacillus delphinicola. Three adult striped dolphins, all stranded in 2018, died of meningoencephalitis suggestive of viral infection, but the etiological agent could not be determined. Bacterial isolation for Brucella was unsuccessful, and CeMV could not be detected. $P$. damselae was isolated in many organs of one of these dolphins, but the observed lesion was suggestive of a viral cause, and not bacterial. Investigations for other viruses were not carried out.

\subsection{Other non-infectious causes of mortality}

Multifocal necrosis of cortical grey matter (encephalomalacia) of unknown origin was observed in the brain of 3 adult striped dolphins (2 females, 1 male). The lesions were multifocal, localized in the cerebral cortical grey matter and were subacute to chronic in nature. Their origin was not evident using histopathology. Infectious agents or vascular lesions were not observed in or close to the lesions.

Multifocal fat necrosis of the blubber, detected as ovoid, irregular, well-delimited brown lesions, was seen in 5 striped dolphins. The cause of these lesions could not be established by histologic investigation, and a direct relationship with the death of the dolphins could not be established. Finally, 2 striped dolphins had tension pneumothoraces (Table 2).

\section{DISCUSSION}

We report on the causes of stranding and death in 89 cetaceans from the Catalonian coast (western Mediterranean Sea) in the period 2012-2019. Except for Balaenoptera physalus $(\mathrm{n}=1)$, all cetaceans belonged to the suborder Odontoceti. Stenella coeruleoalba was the most often stranded and necropsied species, followed by Grampus griseus, Tursiops truncatus and Delphinus delphis. Fisheries interactions represented the most frequent $(28 \%, \mathrm{~N}=89)$ cause of stranding, confirming their continued impact on Mediterranean small cetaceans (Bearzi 2002). The bottlenose dolphin was the most commonly affected species, with $60 \%$ of the 5 necropsied specimens showing clear signs of fisheries interactions or reported as bycatch. In addition, our group detected signs of fisheries interactions in 7 of 8 bottlenose dolphins necropsied between 1994 and 2011 in the same area (M. Domingo et al. unpubl. data). Criteria for diagnosing fisheries interactions are well established internationally, and the risk of overestimating their occurrence in our case series is very low. We provide evidence that CT scans are a reliable technique for the diagnosis of PUE, allowing visualization of gas widely distributed in tissues and cavities, as previously described (Dennison et al. 2012).

Taken together, these data further confirm that fisheries interactions are the most serious threat to the common bottlenose dolphin, as observed in other areas of the Mediterranean Sea (Bearzi et al. 2012). Fisheries interactions were also the main cause of mortality in striped dolphins in our study, with $27.8 \%$ of the 72 specimens affected. The Mediterranean common bottlenose dolphin and striped dolphin are considered 'Vulnerable' by the IUCN (Aguilar \& Gaspari 2012, Bearzi et al. 2012), with fisheries listed as one of the main threats to both species. Our results emphasize the need for specific research on bycatch in the western Mediterranean Sea, since previous studies in these and nearby waters (Balearic Islands, northern Alboran Sea and northern Spain, following GFCM geographical subareas denomination), mostly based on fisherman surveys but also involving onboard observers, did not show such alarming values (Brotons et al. 2008, Gonzalvo et al. 2008, Macías López et al. 2012, Revuelta et al. 2018, ACCOBAMS 2019).

Maternal separation and subsequent starvation were a significant cause of stranding in neonates and calves. Affected individuals were very young, some of them still having foetal folds. They were in poor body condition but did not show any evidence of 
disease and were negative for systemic bacterial infection. As a result of starvation, some calves had different degrees of hepatic lipidosis and some had ingested foreign materials (Lacombe et al. 2020).

CeMV infection and brucellosis were the most significant infectious diseases during the period of this study. A new episode of CeMV circulation, the fourth recorded episode, occurred in the western Mediterranean Sea from September 2016 to September 2017 , and accounted for the death of 13 of 72 (18\%) striped dolphins stranded along the Catalan coast. The first and most severe recorded episode of CeMV mortality occurred from 1990 to 1992, killing hundreds of dolphins (Domingo et al. 1990, 1992, Van Bressem et al. 1991, Duignan et al. 1992, Aguilar \& Raga 1993). It was followed by a second milder episode of mortality from 2006 to 2007 (Fernández et al. 2008, Raga et al. 2008, Soto et al. 2011b). A third small episode of CeMV mortality was reported in 7 striped dolphins (including 2 neonates) stranded along the coast of Valencia in 2012 (Rubio-Guerri et al. 2013). However, for unknown reasons, this CeMV episode was not observed on the Catalonian coast. When compared to previous outbreaks of CeMV-infection (Van Bressem et al. 2014), the 2016-2017 episode displayed different characteristics. Five of the 8 systemic CeMV cases did not have typical CeMV histologic lesions, nor did they test positive using the CeMV-IHC test. However, all affected dolphins had mycotic encephalitis, which, in our experience, has only been observed in striped dolphins during CeMV circulation (Domingo et al. 1992, Soto et al. 2011b). These cases were all positive for CeMV using RTPCR. These observations underline the need to include RT-PCR tests in the surveillance and diagnosis of CeMV infection, and not rely only on histopathology and IHC. After this new episode of CeMV circulation, chronic CeMV infection of the CNS has been detected to date in 5 striped dolphins: 1 in 2017, 3 in 2018 and 1 in 2019. Whole sequencing of CeMV in these cases is planned, to test the hypothesis that the chronic form of the disease is similar to subacute sclerosing panencephalitis (SSPE) in humans or old dog encephalitis (ODE) in canids.

Brucella infection in cetaceans has a worldwide distribution (Nymo et al. 2011, Guzmán-Verri et al. 2012). Since the first recognition of B. ceti-associated disease in cetaceans from the Catalan Mediterranean coast (Isidoro-Ayza et al. 2014) we have modified our necropsy protocol to include a routine BRT for the detection of Brucella antibodies and collection of CSF and organs for specific Brucella bacteriologic isolation. In our study, B. ceti could only be isolated in
8 of the $21(38.1 \%)$ selected cases. Our data indicate that there is a strong correlation between bacterial isolation and the presence of $B$. ceti lesions, such as mononuclear meningitis or spondylitis. At least $7.8 \%$ of the stranded cetaceans examined during this study showed signs of disease associated with B. ceti, mainly neurobrucellosis, confirming the important role of brucellosis in the mortality of stranded cetaceans in the western Mediterranean Sea. The BRT is easy to perform and has been incorporated as an on-site test by rescue teams attending live stranded cetaceans. Nevertheless, a positive result in this test is by no means equivalent to a diagnosis of active brucellosis. Therefore, a positive BRT alone should not influence prognostic decisions when attending live stranded cetaceans.

In the present study there was no clear evidence of association between CeMV disease and active Brucella infection, as only one striped dolphin was infected by both pathogens. Although both CeMV and $B$. ceti can cause CNS lesions, this dolphin had predominantly encephalitic lesions, which are more similar to those induced by CeMV (Van Bressem et al. 2014) than to Brucella-induced mononuclear meningitis (González-Barrientos et al. 2010). Nevertheless, the contribution of each agent to CNS lesions in cases of coinfection may be difficult to discriminate. CeMV causes immunosuppression and may reactivate latent infections such as Toxoplasma spp. or herpesviruses, or facilitate the entry of Aspergillus spp. (Domingo et al. 1992, Soto et al. 2012, Pintore et al. 2018). Similarly, CeMV immunosuppression could cause reactivation of chronic, latent Brucella infections. Possible disease interactions between CeMV and Brucella need further investigation.

Infestation by C. grampicola (Raga et al. 1982) likely caused the stranding and death of 4 of 6 adult Risso's dolphins along the Catalonian coast. Severe Crassicauda spp. infestation may cause the death of immature dolphins following sinusitis, osteomyelitis and sepsis (Dailey \& Stroud 1978, Van Bressem et al. 2020). This parasite may also cause inflammation of the eighth cranial nerve, which dorsally crosses the sinus wall, resulting in disorientation and stranding (Morimitsu et al. 1987). Further investigation into the impact of C. grampicola infestation should include systematic sampling and histologic examination of the eighth cranial nerve and detailed inspection of the skull.

Encephalomalacic changes (necrotic-degenerative lesions in the brain cortex) of unknown origin were detected in 3 striped dolphins $(3.4 \%$ of all cases, $4.2 \%$ of the 72 striped dolphins necropsied). 
In domestic mammals, this kind of lesion is caused by vitamin and/or oligoelement deficient states or by toxic or hypoxic damage to the brain. A similar disease has been described in marine mammals under human care. The diagnosis has often been based on response to treatments (White 1970, Geraci 1981), but in other instances, thiamine deficiency has been confirmed by biochemical analysis (Croft et al. 2013). Although infrequent, this condition deserves more attention, as it has never been reported before in free-ranging cetaceans. Analysis of oligoelements and vitamins in frozen tissues of affected dolphins, and comparison with values in unaffected dolphins, may help to clarify the etiology of this disease.

Lesions and disease of the nervous system were observed in 30 of 89 (33.7\%) of the cetaceans necropsied during this study. This highlights the importance of sampling the brain at necropsy and examining it using histopathology to ensure correct classification of cause of death. Ingestion of abnormal material (e.g. sand, rope, plastic) was not uncommon in our cases (data not shown), but many of the animals ingesting these materials had encephalitis, meningitis, or encephalomalacia. These lesions may explain disorientation and ingestion of foreign material, which would be considered cause of death if only macroscopic examination was performed (Lacombe et al. 2020).

A single case of Sarcocystis spp. hepatic infection was observed in a striped dolphin during the study period. This is a rare infection in dolphins, with only one case diagnosed previously in another Mediterranean Sea striped dolphin (Resendes et al. 2002), indicating a low prevalence of the parasite in the western Mediterranean Sea. Another case was reported in an Indo-Pacific bottlenose dolphin (Tursiops aduncus) kept in captivity in Hong Kong (Calero-Bernal et al. 2017).

Three striped dolphins had wounds with intralesional ciliated protozoa, which reached distant dermis and muscular tissue, causing panniculitis and myositis. These ciliate protozoa (Kyaroikeus spp. or Planilamina spp.) are mostly symbionts of the respiratory tract of cetaceans (Sniezek et al. 1995, Ma et al. 2006), but may invade the dermis through skin lesions (Schulman \& Lipscomb 1999), and extend locally to blubber, subcutaneous tissue and muscular fascia. Ciliated protozoa are usually considered to be opportunistic pathogens, and designating them the cause of death in our cases was done tentatively, in absence of other diseases or lesions. Identification of these protozoa was not attempted.
The cestode $S$. triangularis was found in 4 striped dolphins during the study period. Described in many cetacean species worldwide (Felix 2013), in the Mediterranean Sea it has been reported in $S$. coeruleoalba and T. truncatus (Quiñones et al. 2013). Although it may cause a mild inflammatory reaction, in our cases it was not associated with any major disease or dysfunction.

Three adult striped dolphins, all stranded in 2018, had meningoencephalitis of unknown etiology. The 3 dolphins were negative for Brucella and CeMV. We did not attempt to detect herpesviruses in these lesions, but that may have been the culprit (Van Elk et al. 2016). Targeted investigation for herpesvirus or massive sequencing of brain tissue could help to elucidate the origin of these lesions.

This is the first systematic pathologic investigation of the causes of stranding and death in cetaceans from the Catalonian coast (western Mediterranean) over an 8 yr period. Our data further emphasize the role of bycatch, maternal separation, CeMV and $B$. ceti infection, as well as Crassicauda grampicola sinusitis, as causes of death and stranding in cetaceans in this area and improve our understanding of the factors responsible for morbidity and mortality in these protected species.

Acknowledgements. This research was conducted under a Direcció General de Medi Natural i Biodiversitat Permit. Financial support came from the Direcció General de Medi Natural i Biodiversitat, Generalitat de Cataluny, and the Servei de Vida Silvestre Conselleria d'Agricultura Medi Ambient Canvi Climàtic i Desenvolupament Rural, Generalitat Valenciana. We thank the Laboratorio de Brucelosis del CITA de Aragón for Brucella isolation and BRT. We thank also Blanca Pérez and Aida Neira from the Servei de Diagnòstic de Patologia Veterinària, Universitat Autònoma de Barcelona, and Maite Martin and Marta Perez from IRTACReSA. Finally, we thank the Xarxa de Rescat de Mamifers Marins de la Generalitat de Catalunya and the Cos d'Agents Rurals for their invaluable collaboration.

\section{LITERATURE CITED}

ACCOBAMS (2019) Review of bycatch rates of cetaceans in the Mediterranean Sea and the Black Sea. ACCOBAMSMOP7/2019/Doc29

Aguilar A, Borrell A (1994) Abnormally high polychlorinated biphenyl levels in striped dolphins (Stenella coeruleoalba) affected by the 1990-1992 Mediterranean epizootic. Sci Total Environ 154:237-247

*Aguilar A, Gaspari S (2012) Stenella coeruleoalba (Mediterranean subpopulation). IUCN Red List of Threatened Species 2012: e.T16674437A16674052. http://dx.doi.org/ 10.2305/IUCN.UK.2012-1.RLTS.T16674437A16674052.en

Aguilar A, Raga JA (1993) The striped dolphin epizootic in the Mediterranean Sea. Ambio 22:524-528 
Alba P, Terracciano G, Franco A, Lorenzetti S and others (2013) The presence of Brucella ceti ST26 in a striped dolphin (Stenella coeruleoalba) with meningoencephalitis from the Mediterranean Sea. Vet Microbiol 164: 158-163

Avila IC, Kaschner K, Dormann CF (2018) Current global risks to marine mammals: taking stock of the threats. Biol Conserv 221:44-58

* Aznar FJ, Balbuena J, Raga JA (1994) Are epizoites biological indicators of a western Mediterranean striped dolphin die-off? Dis Aquat Org 18:159-163

* Aznar FJ, Perdiguero D, Pérez Del Olmo A, Repullés A, Agustí C, Raga JA (2005) Changes in epizoic crustacean infestations during cetacean die-offs: the mass mortality of Mediterranean striped dolphins Stenella coeruleoalba revisited. Dis Aquat Org 67:239-247

Bearzi G (2002) Interaction between cetaceans and fisheries in the Mediterranean Sea. In: Notarbartolo-di-Sciara G (ed) Cetaceans of the Mediterranean and Black Seas: state of knowledge and conservation strategies. A report to the ACCOBAMS Secretariat, Section 9, Monaco

* Bearzi G, Notarbartolo-di-Sciara G, Politi E (1997) Social ecology of bottlenose dolphins in the Kvarneric (northern Adriatic Sea). Mar Mamm Sci 13:650-668

* Bearzi G, Reeves RR, Remonato E, Pierantonio N, Airoldi S (2011) Risso's dolphin Grampus griseus in the Mediterranean Sea. Mamm Biol 76:385-400

Bearzi G, Fortuna C, Reeves R (2012) Tursiops truncatus (Mediterranean subpopulation). IUCN Red List of Threatened Species 2012: e.T16369383A16369386. http://dx.doi.org/ 10.2305/IUCN.UK.2012-1.RLTS.T16369383A16369386.en

Kernaldo de Quirós YB, Hartwick M, Rotstein DS, Garner MM and others (2018) Discrimination between bycatch and other causes of cetacean and pinniped stranding. Dis Aquat Org 127:83-95

Brotons JM, Grau AM, Rendell L (2008) Estimating the impact of interactions between bottlenose dolphins and artisanal fisheries around the Balearic Islands. Mar Mamm Sci 24:112-127

Calero-Bernal R, Mauroo NF, Hui SW, Kuiken T and others (2017) Acute fatal sarcocystosis hepatitis in an IndoPacific bottlenose dolphin (Tursiops aduncus) in Hong Kong. Vet Parasitol 235:64-68

Calzada N, Aguilar A, Lockyer C, Grau E (1997) Patterns of growth and physical maturity in the western Mediterranean striped dolphin, Stenella coeruleoalba (Cetacea: Odontoceti). Can J Zool 75:632-637

* Croft L, Napoli E, Hung CK, St. Leger J and others (2013) Clinical evaluation and biochemical analyses of thiamine deficiency in pacific harbor seals (Phoca vitulina) maintained at a zoological facility. J Am Vet Med Assoc 243: 1179-1189

* Cvetnić Ž, Duvnjak S, Đuras M, Gomerčić T, Reil I, ZdelarTuk M, Špičić S (2016) Evidence of Brucella strain ST27 in bottlenose dolphin (Tursiops truncatus) in Europe. Vet Microbiol 196:93-97

Dailey M, Stroud R (1978) Parasites and associated pathology observed in cetaceans stranded along the Oregon coast. J Wildl Dis 14:503-511

* Dennison S, Fahlman A, Moore M (2012) The use of diagnostic imaging for identifying abnormal gas accumulations in cetaceans and pinnipeds. Front Physiol 3:181

Di Guardo G, Mazzariol S, Fernández A (2011) Biologically threatened dolphins and whales. Environ Microbiol 13: 2833-2834
Domingo M, Ferrer L, Pumarola M, Marco A and others (1990) Morbillivirus in dolphins. Nature 348:21

* Domingo M, Visa J, Pumarola M, Marco AJ, Ferrer L, Rabanal R, Kennedy S (1992) Pathologic and immunocytochemical studies of morbillivirus infection in striped dolphins (Stenella coeruleoalba). Vet Pathol 29: $1-10$

* Domingo M, Vilafranca M, Visa J, Prats N, Trudgett A, Visser I (1995) Evidence for chronic morbillivirus infection in the Mediterranean striped dolphin (Stenella coeruleoalba). Vet Microbiol 44:229-239

* Duignan PJ, Geraci JR, Raga JA, Calzada N (1992) Pathology of morbillivirus infection in striped dolphins (Stenella coeruleoalba) from Valencia and Murcia, Spain. Can J Vet Res 56:242-248

Felix JR (2013) Reported incidences of parasitic infections in marine mammals from 1892 to 1978. Zea Books, Lincoln, NE

*Fernández A, Esperon F, Herraéz P, De Los Monteros AE and others (2008) Morbillivirus and pilot whale deaths, Mediterranean Sea. Emerg Infect Dis 14:792-794

* Fraija-Fernández N, Aznar FJ, Fernández A, Raga JA, Fernández M (2016) Evolutionary relationships between digeneans of the family Brachycladiidae Odhner, 1905 and their marine mammal hosts: a cophylogenetic study. Parasitol Int 65:209-217

*Fraija-Fernández N, Fernandez M, Lehnert K, Raga JA, Siebert U, Aznar FJ (2017) Long-distance travellers: phylogeography of a generalist parasite, Pholeter gastrophilus, from cetaceans. PLOS ONE 12:e0170184

*Fraija-Fernández N, Hernández-Hortelano A, Ahuir-Baraja AE, Raga JA, Aznar FJ (2018) Taxonomic status and epidemiology of the mesoparasitic copepod Pennella balaenoptera in cetaceans from the western Mediterranean. Dis Aquat Org 128:249-258

Garofolo G, Zilli K, Troiano P, Petrella A and others (2014) Brucella ceti from two striped dolphins stranded on the Apulia coastline, Italy. J Med Microbiol 63:325-329

*Geraci JR (1981) Dietary disorders in marine mammals: synthesis and new findings. J Am Vet Med Assoc 179: 1183-1191

*González-Barrientos R, Morales JA, Hernández-Mora G, Barquero-Calvo E, Guzmán-Verri C, Chaves-Olarte E, Moreno E (2010) Pathology of striped dolphins (Stenella coeruleoalba) infected with Brucella ceti. J Comp Pathol 142:347-352

* Gonzalvo J, Valls M, Cardona L, Aguilar A (2008) Factors determining the interaction between common bottlenose dolphins and bottom trawlers off the Balearic Archipelago (western Mediterranean Sea). J Exp Mar Biol Ecol 367:47-52

* Guzmán-Verri C, González-Barrientos R, Hernández-Mora G, Morales J, Baquero-Calvo E, Chaves-Olarte E, Moreno E (2012) Brucella ceti and brucellosis in cetaceans. Front Cell Infect Microbiol 2:1-22

*Hammond PS, Bearzi G, Bjørge A, Forney K, Karczmarski L, Kasuya T, Perrin WF, Scott MD, Wang JY, Wells RS, Wilson B (2008) Delphinus delphis, short-beaked common dolphin. IUCN Red List of Threatened Species 2008: e.T6336A12649851. http://dx.doi.org/10.2305/IUCN.UK. 2008.RLTS.T6336A12649851.en

光Isidoro-Ayza M, Ruiz-Villalobos N, Pérez L, Guzmán-Verri C and others (2014) Brucella ceti infection in dolphins from the western Mediterranean sea. BMC Vet Res 10: 206 
Klotz D, Hirzmann J, Bauer C, Schöne J and others (2018) Subcutaneous merocercoids of Clistobothrium sp. in two Cape fur seals (Arctocephalus pusillus pusillus). Int $\mathrm{J}$ Parasitol Parasites Wildl 7:99-105

Krafft A, Lichy JH, Lipscomb TP, Klaunberg BA, Kennedy S, Taubenberger JK (1995) Postmortem diagnosis of morbillivirus infection in bottlenose dolphins (Tursiops truncatus) in the Atlantic and Gulf of Mexico epizootics by polymerase chain reaction-based assay. J Wildl Dis 31: 410-415

Kuiken T (1991) Cetacean pathology: dissection techniques and tissue sampling. Proc first ECS workshop. https:// www.europeancetaceansociety.eu/system/files/ECS Special Publication Series/Newsletter 17.pdf

Lacombe A, Pintado E, O'Byrne A, Allepuz A, PerezRodriguez MD, Domingo M (2020) Ingestion of foreign materials in odontocetes in the Catalan Coast, causes and consequences. Dis Aquat Org 142:23-31

Law RJ (2014) An overview of time trends in organic contaminant concentrations in marine mammals: going up or down? Mar Pollut Bull 82:7-10

Ma H, Overstreet RM, Sniezek JH, Solangi M, Wayne Coats D (2006) Two new species of symbiotic ciliates from the respiratory tract of cetaceans with establishment of the new genus Planilamina n. gen. (Dysteriida, Kyaroikeidae). J Eukaryot Microbiol 53:407-419

* Macías López D, García Barcelona S, Báez JC, de la Serna JM, Ortiz de Urbina JM (2012) Marine mammal bycatch in Spanish Mediterranean large pelagic longline fisheries, with a focus on Risso's dolphin (Grampus griseus). Aquat Living Resour 25:321-331

Mateu P, Raga JA, Aznar FJ (2011) Host specificity of Oschmarinella rochebruni and Brachycladium atlanticum (Digenea: Brachycladiidae) in five cetacean species from western Mediterranean waters. J Helminthol 85:12-19

Mateu P, Raga JA, Fernández M, Aznar FJ (2014) Intestinal helminth fauna of striped dolphins (Stenella coeruleoalba) in the western Mediterranean: no effects of host body length, age and sex. Mar Mamm Sci 30:961-977

* Moore MJ, Van Der Hoop J, Barco SG, Costidis AM and others (2013) Criteria and case definitions for serious injury and death of pinnipeds and cetaceans caused by anthropogenic trauma. Dis Aquat Org 103:229-264

Morimitsu T, Nagai T, Ide M, Kawano H, Naichuu A, Koono M, Ishii A (1987) Mass stranding of Odontoceti caused by parasitogenic eighth cranial neuropathy. J Wildl Dis 23: 586-590

Notarbartolo-Di-Sciara G (2014) Sperm whales, Physeter macrocephalus, in the Mediterranean Sea: a summary of status, threats, and conservation recommendations. Aquat Conserv 24:4-10

Nymo IH, Tryland M, Godfroid J (2011) A review of Brucella infection in marine mammals, with special emphasis on Brucella pinnipedialis in the hooded seal (Cystophora cristata). Vet Res 42:93

OIE (2019) Manual of diagnostic tests and vaccines for terrestrial animals, Chapter 3.1.4. https://www.oie.int/ fileadmin/Home/eng/Health_standards/tahm/3.01.04_ BRUCELLOSIS.pdf

* Panigada S, Notarbartolo-di-Sciara G (2012) Balaenoptera physalus (Mediterranean subpopulation), fin whale. IUCN Red List of Threatened Species 2012: e.T16208224A17549588. http://dx.doi.org/10.2305/IUCN. UK.2012.RLTS.T16208224A17549588.en

* Panigada S, Pesante G, Zanardelli M, Capoulade F, Gannier
A, Weinrich MT (2006) Mediterranean fin whales at risk from fatal ship strikes. Mar Pollut Bull 52:1287-1298

*Pérez L, Abarca ML, Latif-Eugenín F, Beaz-Hidalgo R, Figueras MJ, Domingo M (2015) Aeromonas dhakensis pneumonia and sepsis in a neonate Risso's dolphin Grampus griseus from the Mediterranean Sea. Dis Aquat Org 116:69-74

Pintore MD, Mignone W, Di Guardo G, Mazzariol S and others (2018) Neuropathologic findings in cetaceans stranded in Italy (2002-2014). J Wildl Dis 54:295-303

* Pinzone M, Budzinski H, Tasciotti A, Ody D and others (2015) POPs in free-ranging pilot whales, sperm whales and fin whales from the Mediterranean Sea: influence of biological and ecological factors. Environ Res 142:185-196

*Quiñones R, Giovannini A, Raga JA, Fernández M (2013) Intestinal helminth fauna of bottlenose dolphin Tursiops truncatus and common dolphin Delphinus delphis from the western Mediterranean. J Parasitol 99:576-579

Raga JA, Casinos A, Filella S, Raduan A (1982) Notes on cetaceans of the Iberian coasts. V. Crassicauda grampicola Johnston \& Mawson, 1941, (Nematoda) cause of injuries in the pterygoids of some specimens of Grampus griseus. Saugetierkdl Mitt 30:315-318

Raga JA, Banyard A, Domingo M, Corteyn M and others (2008) Dolphin morbillivirus epizootic resurgence, Mediterranean Sea. Emerg Infect Dis 14:471-473

* Resendes AR, Juan-Sallés C, Almeria S, Majó N, Domingo M, Dubey JP (2002) Hepatic sarcocystosis in a striped dolphin (Stenella coeruleoalba) from the Spanish Mediterranean Coast. J Parasitol 88:206-209

* Revuelta O, Domènech F, Fraija-Fernández N, Gozalbes $P$, Novillo O, Penadés-Suay J, Tomás J (2018) Interaction between bottlenose dolphins (Tursiops truncatus) and artisanal fisheries in the Valencia region (Spanish Mediterranean Sea). Ocean Coast Manage 165:117-125

* Rubio-Guerri C, Melero M, Esperón F, Bellière EN and others (2013) Unusual striped dolphin mass mortality episode related to cetacean morbillivirus in the Spanish Mediterranean Sea. BMC Vet Res 9:106

* Schoeman RP, Patterson-Abrolat C, Plön S (2020) A global review of vessel collisions with marine animals. Front Mar Sci 7:1-25

Schulman FY, Lipscomb TP (1999) Dermatitis with invasive ciliated protozoa in dolphins that died during the 19871988 Atlantic bottlenose dolphin morbilliviral epizootic. Vet Pathol 36:171-174

* Silvani L, Gazo M, Aguilar A (1999) Spanish driftnet fishing and incidental catches in the western Mediterranean. Biol Conserv 90:79-85

* Sniezek JH, Coats DW, Small EB (1995) Kyaroikeus cetarius N.G., n. sp.: a parasitic ciliate from the respiratory tract of odonticete cetacea. J Eukaryot Microbiol 42:260-268

Soto S, Alba A, Ganges L, Vidal E and others (2011a) Postepizootic chronic dolphin morbillivirus infection in Mediterranean striped dolphins Stenella coeruleoalba. Dis Aquat Org 96:187-194

Soto S, Marco A, Domingo M, González R and others (2011b) Epizootic of dolphin morbillivirus on the Catalonian Mediterranean coast in 2007. Vet Rec 169:101

* Soto S, González B, Willoughby K, Maley M and others (2012) Systemic herpesvirus and morbillivirus co-infection in a striped dolphin (Stenella coeruleoalba). J Comp Pathol 146:269-273

Storelli MM, Barone G, Piscitelli G, Storelli A, Marcotrigiano GO (2007) Tissue-related polychlorinated biphenyls accu- 
mulation in Mediterranean cetaceans: Assessment of toxicological status. Bull Environ Contam Toxicol 78: 206-210

Tudela S, Kai Kai A, Maynou F, El Andalossi M, Guglielmi P (2005) Driftnet fishing and biodiversity conservation: the case study of the large-scale Moroccan driftnet fleet operating in the Alboran Sea (SW Mediterranean). Biol Conserv 121:65-78

Van Bressem MF, Visser IK, Van de Bildt MW, Teppema JS, Raga JA, Osterhaus AD (1991) Morbillivirus infection in Mediterranean striped dolphins (Stenella coeruleoalba). Vet Rec 129:471-472

Van Bressem MF, Waerebeek K, Raga JA, Godfroid J, Brew SD, MacMillan AP (2001) Serological evidence of Brucella species in odontocetes from the south Pacific and the Mediterranean. Vet Rec 148:657-661

Van Bressem MF, Raga JA, Di Guardo G, Jepson PD and others(2009) Emerging infectious diseases in cetaceans worldwide and the possible role of environmental stressors. Dis Aquat Org 86:143-157

Editorial responsibility: Stephen Raverty, Abbotsford, British Columbia, Canada
Van Bressem MF, Duignan PJ, Banyard A, Barbieri M and others (2014) Cetacean morbillivirus: current knowledge and future directions. Viruses 6:5145-5181

*Van Bressem MF, Duignan P, Raga J, Van Waerebeek K, Fraijia-Fernández N, Plön S (2020) Cranial crassicaudiasis in Indian Ocean humpback dolphins and Indo-Pacific bottlenose dolphins from South Africa is predominantly a disease of immature individuals. Dis Aquat Org 139: 93-102

*Van Elk C, Van De Bildt M, Van Run P, De Jong A and others (2016) Central nervous system disease and genital disease in harbor porpoises (Phocoena phocoena) are associated with different herpesviruses. Vet Res 47:28

*Van Waerebeek K, Baker AN, Félix F, Gedamke J and others (2007) Vessel collisions with small cetaceans worldwide and with large whales in the Southern Hemisphere, an initial assessment. Lat Am J Aquat Mamm 6:43-69

White JR (1970) Thiamine deficiency in an Atlantic bottlenosed dolphin (Tursiops truncatus) on a diet of raw fish. J Am Vet Med Assoc 157:559-562

Submitted: May 27, 2020; Accepted: October 14, 2020 Proofs received from author(s): December 9, 2020 